University of Rhode Island

DigitalCommons@URI

Open Access Master's Theses

1983

\title{
The Use of Isolate Children as Peer Modifiers in the Treatment of Social Skills Deficits
}

Diane Marques

University of Rhode Island

Follow this and additional works at: https://digitalcommons.uri.edu/theses

\section{Recommended Citation}

Marques, Diane, "The Use of Isolate Children as Peer Modifiers in the Treatment of Social Skills Deficits" (1983). Open Access Master's Theses. Paper 1593.

https://digitalcommons.uri.edu/theses/1593

This Thesis is brought to you for free and open access by DigitalCommons@URI. It has been accepted for inclusion in Open Access Master's Theses by an authorized administrator of DigitalCommons@URI. For more information, please contact digitalcommons-group@uri.edu. 
THE USE OF ISOLATE CHILDREN

AS PEER MODIFIERS IN THE TREATMENT

OF SOCIAL SKILIS DEFICITS

BY

DIANE MARQUES

A THESIS SUBMITTED IN PARTIAL FULFILLMENT OF THE REQUIREMENTS FOR THE DEGREE OF

MASTER OF ARTS

IN

CLINICAL PSYCHOLOGY

UNIVERSITY OF RHODE ISLAND

1983 
Increasing amounts of attention have been paid in recent years to the effects of peer interaction on healthy development in children. The present study taught isolate children to act as peer modifiers in a semi-structured play group, delivering reinforcement for two classes of play initiations. Frequency of the two classes of play initiations, amount of positive reinforcement delivered, negative behavior and hovering emitted by isolates was recorded on a daily basis in a free play session preceding treatment.

Five isolate children were selected using the standardized criteria in the Social Assessment Manual for Preschool Level. Using a multiple baseline across subjects design, isolates participated in half-hour play sessions four consecutive days per week over 36-40 days. Data were analyzed using graphical and time series analysis. Three week and six month follow-up of isolate children was conducted.

The five isolate peer modifiers displayed significant increases in play initiations as a function of treatment, which were maintained at three week and six month follow-up. Standardized assessment measures placed the subjects in nonisolate ranges of social skills at three week and six month follow-up. Vicarious and natural reinforcement contingencies may account for the long-term intervention effects. 
TABLE OF CONTENTS

$\underline{\text { Page }}$

ABSTRACT . . . . . . . . . . . . . . . . ii LIST OF TABLES ................... . . iv LIST OF FIGURES . . . . . . . . . . . . . . V V INTRODUCTION . . . . . . . . . . . . . . 1 METHODOLOGY . . . . . . . . . . . . . 5 RESULTS . . . . . . . . . . . . . 14 DISCUSSION . . . . . . . . . . . . . 18 REFERENCES . . . . . . . . . . . . . . 34 APPENDICES

I. Informed Consent . . . . . . . . . 39

II. Daily Record Sheet... . . . . . . . . 43

III. Summary of Non-Isolate Data . . . . . . 44 


\section{LIST OF TABLES}

1. Inter-rater Reliability

Estimates Per Subject

2. Isolate Means of Daily

Frequency iveasures Per Phase

3. Between Phase Comparisons of

Vocal-verbal and Motor-Gestural

Behaviors Per Subject Using

Time Series Analysis

4. Isolate Scores on the SBR+ 31

5. Isolate Scores on the sos 32

6. Repeated Measures ANOVA For Isolate 33

Group Means on SAMPLE Measures 
1. Isolate Vocal-verbal and Motor25 Gestural Play Initiations Across Experimental Phases. 
Peer interaction plays a significant role in the healthy development of children. Numerous studies have associated peer acceptance with academic achievement, cognitive and emotional development, and subsequent adult functioning (Cobb, 1970; Roff, 1961; UlImann, 1957). Conversely, deficient peer relations have been associated with school difficulties, juvenile delinquency, and later psychiatric contacts (Cowen, Pederson, Babijian, Izzo \& Trost, 1973).

Although the literature lacks consensus on the critical determinants of social competence (Conger \& Keane, 1981), popular children seem to emit and receive more positive reinforcement than unpopular peers (Charlesworth \& Hartup, 1967). When children are unable to express themselves in socially appropriate ways, positive reinforcement from adults and peers rapidly diminishes (Michelson \& Wood, 1980), and competent behaviors are frequently ignored, resulting in further isolation (Strain \& Kerr, 1981).

Previous social skills interventions to remediate isolation, or extreme levels of social withdrawal, fall into three broad categories: modeling techniques, peer initiation strategies, and operant reinforcement procedures. Modeling techniques have successfully increased social interaction levels in groups of isolate children 
using either a symbolic approach, in which isolates view films of confederate children successfully engaging in play (O'Connor, 1969, 1972), or a live modeling format, in which trained peers model play skills such as sharing or starting interaction in the isolate's presence (Cooke, Cooke \& Apolloni, 1978; Peck, Apolloni, Cooke, \& Raven, 1978). Peer initiation strategies have demonstrated that spontaneous play initiations may be facilitated in normal isolates (Strain \& Kerr, 1981), mentally retarded (Strain, Shores \& Kerr, 1977), and autistic (Strain \& Timm, 1974) children by training confederate classmates to repeatedly initiate play with isolate subjects. Finally, reinforcement techniques using contingent adult reinforcement for such behaviors as play initiations, positive responding or complimenting have resulted in immediate increases of the reinforced skill in isolates (Allen, Hart, Buell, Harris \& Wolf, 1964; Hymel \& Asher, 1977), with group reward of isolates and non-isolates yielding more and faster change than individual contingencies (Walker, Greenwood, Hops, \& Todd, 1979).

All three classes of social skills interventions have resulted in at least temporary skill gains in isolates, however the long-term effects of treatment have been disappointing (Conger \& Keane, 1981). Poor generalization and maintenance of trained skills are the primary 
drawbacks of each technique, but for different reasons. Specifically, modeling techniques tend to be ineffective if the child cannot or does not attend to the displayed behaviors (O'Connor, 1969); peer initiation strategies rely on trained confederates to increase isolate responding, and do not focus on specific skill acquisition (Strain \& Kerr, 1981); and operant interventions generally lack the modeling opportunities of other techniques, and are rate dependent on the isolate baseline skill level (Hymel \& Asher, 1977). Adult reinforcement may also interrupt the interaction process (Cooke, Cooke, \& Apolloni, 1978) with poor generalization and maintenance of skill gains resulting if not enhanced by peer reinforcement (Combs \& Slaby, 1977).

A parallel area of research involves the use of peers to administer classroom contingencies. Competent peers have been taught to successfully deliver reinforcement for academic, social and appropriate classroom behaviors with normal (Phillips, Phillips, Wolf \& Fixen, 1973; Suratt, Ulrich \& Hawkins, 1969), autistic (Strain, Kerr \& Ragland, 1977), and mentally retarded (Lancioni, 1982; Wiesen, Hartley, Richardson \& Raske, 1967) populations. Siegal and Steinman (1975) is the only study which systematically observed the changes in peer modifiers' behavior as a function of delivering reinforcement to less 
skilled peers. Peer modifiers themselves increased in on-task academic behaviors as a function of observation and reinforcement delivery for these behaviors, i.e. vicarious reinforcement. In other words, expectation of reinforcement stimulated emission of the target behavior in non-reinforced subjects.

A novel intervention to remediate social skills deficits which incorporates the advantages of each reviewed technique is to use the isolate child as a peer modifier. By acting as a peer modifier delivering reinforcement for appropriate social behaviors, the isolate child assumes a positively reinforcing function with peers, and participates in reward contingencies. Simultaneously, the isolate child should increase in the target behaviors and receive a maximal amount of modeling from competent peers. By not being labeled as a problem student, the isolate child bypasses a reactive or less competent role in the group.

The purpose of the present study was to teach isolate pre-schoolers to deliver reinforcement to socially competent peers for two categories of play initiations in a semi-structured play setting. It was expected that both isolates and peers would increase in vocalverbal and motor-gestural play initiations as a function of delivering or receiving reinforcement. 


\section{METHOD}

Setting

The investigation was conducted at a private preschool serving a suburban, working and middle class community. Children attended the school Monday through Friday from 9 to $11: 30 \mathrm{~A} . \mathrm{M}$. The study took place during a regularly scheduled free play period Monday through Thursday from 9 to $9: 30 \mathrm{~A} . \mathrm{M}$. During the first 15 mins. of this period, the children had free access to blocks, tinker toys, dolls and art materials in a large unpartitioned room with tables and chairs in various corners. Treatment took place during the following 15 mins. with the participants sitting on benches around a large table in a corner of the room.

\section{Subjects}

Five isolate and five non-isolate four year olds were selected from three classes of 34 children using the multiple criteria outlined in the Social Assessment Manual for Pre-school Level - SAMPLE (Greenwood, Todd, Walker \& Hops, 1978). The isolate group was comprised of three boys and two girls, and the non-isolate group contained the same number of boys and girls as the treatment group. SAMPLE is a standardized assessment package to identify social isolation or social skills deficits in the pre-school 
population, and was normed on 1000 four and five year olds. Standardized selection measures were used as recommended by Conger and Keane (1981) to clearly delineate the treatment population for increased generalizability of the research findings. Inclusion criteria for the isolate group were isolate range scores on three SAMPLE measures completed by the teachers and investigators in consecutive order. After five children were determined as within isolate ranges on all SAMPLE measures, five non-isolates were chosen randomly from teachers' lists. SAMPLE assessment measures were administered in the following order: Isolates

Teacher Frequency Ranking (TFR) - Teachers from three classes used this measure to rank pupils who spoke least in class. The three lowest interactors were chosen from each teacher's list for further assessment, yielding a sample of nine possible isolates from a pool of 34 children.

Social Behavior Rating Positive Scale (SBR+) Teachers used this measure as the second step in the identification of isolates. The measure yields a profile of a child's performance in nine social skill strength areas. Five of the nine children ranked as speaking least in class received isolate scores on the SBR+. 
Sample Observation System (SOS) - Children receiving isolate scores on both the TFR and SBR+ were then observed by the investigators using the SOS. The SOS is a standardized scoring system which yields an interaction rate that can be compared to SAMPLE norms. The latter five children all fell within isolate norms on the sos and thus met the inclusion criteria of isolate range scores on the three SAMPLE measures.

\section{Non-isolates}

Three boys and two girls were then randomly selected from teachers' lists. Inclusion criteria consisted of non-isolate range scores on the TFR and SOS. All five children fell within average ranges on these measures, which were included as checks to verify that the randomly chosen were non-isolates.

\section{Target Behaviors}

Undergraduate observers recorded target behaviors on a record sheet prepared by the investigator using Greenwood and Hops (1979) suggestions regarding clarity and quick scanning (See Appendix II).

Observers recorded target behaviors during routine free play from 9 to $9: 15 \mathrm{~A} . \mathrm{M}$. Data were collected daily for isolates and three times per experimental phase for 
non-isolates. Observers recorded the frequency of the following five classes of behavior:

\section{Vocal-verbal Play Initiations - All statements}

emitted while one child faced another which represented attempts to start play (Strain \& Timm, 1974) by a) soliciting the involvement of other children (e.g. "Mary, come play with me."), b) attempting to share materials (e.g. "Would you like to use my crayon?"), or structuring play (e.g. "Let's take turns.").

\section{Motor-Gestural Play Initiations - All gestures} emitted while one child faced another which represented attempts to start play such as waves, pats, hugs, kisses or touching hands (Strain \& Timm, 1974).

\section{Positive Reinforcement - All statements emitted} which expressed like, approval or affection in the form of praise or compliments.

Negative Behaviors - Any behavior which was negative or destructive such as verbal insults or physical assaults.

Hovering - Any instance of a child standing within one foot of a group silently observing play.

The latter five classes of behavior were chosen for observation because of their frequent appearance in the social skills literature. A serious methodological 
criticism of the literature is the difficulty in analyzing treatment outcome across studies due to the disparate dependent variables used (Conger \& Keane, 1981). Vocalverbal and motor-gestural play initiations were thus chosen as dependent measures because of their concise definition and popularity in the treatment of pre-schoolers (Strain \& Kerr, 1981). Positive reinforcement delivery, negative and hovering behaviors were included to assess any concommitent changes in the topography of the children's social behavior as a function of treatment (Hops \& Greenwood, 1979).

\section{Observation Procedures}

Target behaviors between isolates and peers were recorded for 30 consecutive intervals during the daily 15 min. free play period between 9 and 9:15 A.M. Trained undergraduate observers used a numerical recording system on a prepared record sheet. Each 30 sec. interval was divided into a 20 sec. observation block followed by a 10 sec. recording block to structure inter-rater reliability calculations. Observers were blind to subject selection and nature of treatment. Each undergraduate observer was randomly assigned to observe a different participant (isolate or non-isolate) every day. Observers stationed themselves between four and six feet from the subject, in unobtrusive places such as along walls or 
in corners. The students expressed little interest in the observers since student teachers routinely observed the setting.

observers received 10 hours of pre-training over a three week period before entering the setting. Instructional handouts and pre-school age live models were used in practice sessions outside the setting. Inter-rater reliability was assessed in the setting every third observation for each participant. Percent agreement occurence and non-occurence of behavior was determined by pairing one of two "reliability observers" with the randomly assigned observer on a rotating basis.

Reliability - Reliability was calculated as number of agreements. Percent agreement occurence and non-occurence of behavior were calculated separately to avoid spuriously high estimates of reliability given the initially low frequency of the target behaviors. Interrater reliability was calculted for each isolate participant, and is included in Table 1. Inter-rater reliability estimates ranged from .89 to $.96(\bar{X}=.93)$ percent agreement occurence of behavior and .96 to $.98(\overline{\mathrm{X}}=.97)$ agreement non-occurence of behavior across subjects and represent observations over 360 intervals or one-third of session days per isolate. 


\section{Experimental Procedure}

Subject participation ranged from 36 to 40 days per student. A staggered multiple baseline across subjects design was employed, in which interventions were introduced at intervals of varying length across the five subjects. This "staggering" of interventions allowed analysis of individual treatment effects while controlling for possible group reactivity. The multiple baseline design permitted causal inference by establishing baseline rates for two dependent variables while no intervention occured. An intervention was then introduced which affected only one of the variables, while the untreated variables remained constant. A subsequent intervention was introduced to demonstrate increases in both variables. Procedure varied according to the following experimental phases.

Baseline - Five isolates were observed in the free play situation with no experimental intervention for 10 days (Subject 1 ), 12 days (Subjects 2 \& 3), or 14 days (Subjects 4 \& 5 ).

Instructional Phase - Each isolate child was approached individualy by the investigator and asked to participate as peer modifier in the group. The investigator explained, "(I'm) doing a play group to help children learn how to 
play together more, and (I'd) like you to be my helper." The isolates were then asked, "What kinds of things do you do when you want to start to play with someone?" If a vocal-verbal or motor-gestural play initiation was labeled, the child was told "That's right." If a child emitted an inappropriate response or remained silent, the investigator asked "Is ... a good way to start to play?" This process continued until all of the previously defined vocal-verbal and motor-gestural target behaviors were named. The isolates were then shown the tokens $\mathrm{s}(\mathrm{he})$ was to deliver to non-isolates. Isolates were deemed ready to be peer modifiers when they could identify at least four vocal-verbal or motor-gestural play initiations in a yes/no format. Each child completed this phase within four days.

Intervention I - Following free play observation, the five isolates and five non-isolates gathered around the play table. Blocks, tinker toys and art materials were placed on the table prior to the session. Each isolate peer modifier was randomly assigned to observe a non-isolate peer. The reinforcement contingencies were explained to the children during the first session. The isolate's task was to tell the investigator when $\mathbf{s}($ he) saw the peer emit a vocal-verbal play initiation, and deliver a token and praise to the non-isolate for 
this behavior. The isolate in turn received the same reinforcement from the investigator for accurate observation and delivery of praise and tokens. Tokens were traded in at the end of the play period for inexpensive play items such as stickers or plastic animals.

\section{Intervention II - This phase was identical to} Intervention I with the exception that isolate peer modifiers delivered praise and tokens for motor-gestural play initiations in addition to vocal-verbal behaviors. The new contingencies were explained to the participants on the first day of Intervention II, and isolate children needed no prompting to independently deliver reinforcement for the new behavior after the contingencies were explained.

\section{Post-treatment Assessment - Post-treatment assessment} data were collected three weeks and six months after the final treatment day. At three week follow-up, teachers completed the SBR+ for isolates, investigators completed the SOS for isolates and non-isolates, and observers recorded frequencies of target behaviors over a three day period. At six month follow-up, new teachers completed the SBR+, and investigators completed the SOS and recorded frequencies of the target behaviors for each isolate child. 


\section{RESULTS}

The effects of delivering reinforcement for play initiations on isolate children were evaluated using descriptive and quantitative methods for daily frequency measures, and two standardized SAMPLE measures used at pre- and post-treatment. Descriptive analysis consisted of graphical representation of the data, and quantitative analysis was performed using time-series statistics. Time-series analysis was conducted using the Autoregressive Integrated Moving Averages model - ARIMA (Glass, Wilson \& Gottman, 1975). Because the number of pre-intervention observations was inadequate for model identification, an ARIMA $(1,0,0)$ model was assumed following the suggestion of Simonton (1977). Research suggests the $(1,0,0)$ model may be appropriate in a variety of applications (Harrop \& Vellicer, 1982). Only level and changes in level parameters were fit.

Daily Frequency Measures - The five isolate peer modifiers displayed increases in vocal-verbal and motorgestural play initiations as a function of delivering reinforcement for these behaviors during treatment. Figure 1 shows frequencies of the target behaviors across experimental phases for each isolate. Results will be reviewed per subject. 
Vocal-verbal and motor-gestural behaviors were infrequent during baseline and instructional phases for Subject $1\left(\overline{\mathrm{X}}_{\mathrm{V}}=1 \cdot 3 ; \overline{\mathrm{X}}_{\mathrm{M}}=0.2\right)$. Intervention $I$ consisted of isolate children delivering reinforcement to peers for vocal-verbal play initiations. Subject 1 displayed gradual increases in vocal-verbal behavior (See Figure 1) while motor-gestural behavior remained at baseline levels as expected $\left(\overline{\mathrm{X}}_{\mathrm{V}}=2.7 ; \overline{\mathrm{X}}_{\mathrm{M}}=0.7\right)$. Graphical increases were supported by time-series analysis, and Subject 1 displayed significant increases in vocal-verbal behavior between these phases $(\underline{t}(20)=4.46, \underline{p}=.01)$, while motor-gestural behavior remained at non-significant levels ( $\underline{t}(20)=1.72$, n.s.). Intervention II consisted of isolate children delivering reinforcement to peers for both motor-gestural and vocal-verbal play initiations. Subject 1 displayed immediate increases in motor-gestural behaviors, and continued gains in vocal-verbal behaviors (See Figure 1 $\left.\overline{\mathrm{X}}_{\mathrm{V}}=7.1 ; \overline{\mathrm{X}}_{\mathrm{W}}=2.4\right)$. Statistical significance was found between baseline and Intervention II for both classes of play initiations $\left(\underline{t}_{V}(20)=6.18, \underline{p}=.01 ; \underline{t}_{\mathbb{M}}(20)=7.93\right.$, $\mathrm{p}=.01$ ). Subject 1 maintained gains in vocal-verbal and motor-gestural play initiations at both three week follow-up $\left(\overline{\mathrm{X}}_{\mathrm{V}}=7.3 ; \overline{\mathrm{X}}_{\mathrm{M}}=3.3\right)$, and six month follow-up $\left(x_{V}=6.0: x_{M}=3.0\right)$. This patterm of treatment effects typifies results for subjects 3 and 5 , and complete data 
is included for these subjects in Figure 1, and Tables 2 and 3.

Insert Figure 1 about here

Insert Table 2 about here

Subject 2 displayed low but variable frequencies of vocal-verbal and motor-gestural play initiations $\left(\bar{X}_{\mathrm{V}}=3.0\right.$; $\overline{\mathrm{X}}_{\mathrm{M}}=0.9$ ) during baseline (See Figure 1). Slight increases were seen in vocal-verbal behavior during Intervention I $\left(\overline{\mathrm{X}}_{\mathrm{V}}=5.8 ; \overline{\mathrm{X}}_{\mathrm{M}}=1.0\right)$, with decreases to baseline levels immediately preceding the child's absence due to illness. No significant differences were found between baseline and Intervention I for vocal-verbal or motor-gestural behavior $\left(\underline{t}_{V}(20)=1.93\right.$, n.s; $\left.\underline{t}_{M}(20)=0.18, n . s.\right)$. However, Intervention II resulted in immediate gains in both classes of play initiations $\left(\overline{\mathrm{X}}_{\mathrm{V}}=9.2 ; \overline{\mathrm{X}}_{\mathrm{M}}=2.5\right)$ at significant levels in comparison to baseline $\left(\underline{t}_{V}(20)=6.99, \underline{p}=0.1\right.$; $\left.t_{M}(20)=4.85, \underline{p}=.01\right)$. These gains were maintained at three week follow-up $\left(\overline{\mathrm{X}}_{\mathrm{V}}=6.3 ; \overline{\mathrm{X}}_{\mathrm{M}}=3.0\right)$ and six month follow-up $\left(x_{\mathrm{V}}=11.0 ; \mathrm{x}_{\mathrm{M}}=7.0\right)$. Subject 4 displayed similar patterns of variability and treatment gains, which are summarized in Figure 1 and Tables 2 and 3 . 
Insert Table 3 about here

Frequency data collected for all subjects on the delivery of positive reinforcement, negative behavior and hovering are summarized in Table 2 , and revealed no changes in these low frequency behaviors across phases. Results are congruent with reported frequencies of behavior for this age group (Hops \& Greenwood, 1981).

\section{Insert Table 4 about here}

SAMPLE Measures - Pre- and post-treatment scores on the SBR+ are shown in Table 4. Classroom teachers at the setting completed the $\mathrm{SBR}+$ at pre-treatment and three week follow-up. At six month follow-up, the isolate peer modifiers had entered kindergarten, and five new teachers completed the SBR+. Subject 1 received isolate range scores on the SBR+ at pre- and post-treatment. Although the child's scores reflected skill gains in the areas of joining play groups and engaging in long conversations with other children, improvement was still needed in areas such as volunteering to speak in class. Subject 2 received isolate range scores on the $\mathrm{SBR}+$ at pre-treatment and three week follow-up, but was not perceived in isolate ranges by the new teacher at six month follow-up, as did 
Subject 3. Subjects 4 and 5 initially received isolate scores on the SBR+ at pre-treatment, but were perceived as non-isolates at three week and six month follow-up. A repeated measures ANOVA revealed no significant treatment gains ( $\underline{F}(2,8)=0.6$, n.s. - See Table 6 for complete information).

Insert Table 5 about here

Table 5 summarizes pre- and post-treatment scores on the SOS, a standardized interaction rate measure. All five isolates attained non-isolate scores in the SOS using SAMPIE norms for four year olds. At six month follow-up, all five isolate children attained non-isolate interaction rates using both the four and five year old norms included in SAMPLE. A repeated measures ANOVA revealed significant treatment effects $(\underline{F}(2,8)=5.5$, $p=0.5$ - See Table 6).

\section{Insert Table 6 about here}

\section{DISCUSSION}

The present study demonstrated that isolate children can successfully act as peer modifiers while increasing in the social behaviors they observe and reinforce. These 
increases were of sufficient magnitude to elevate interaction rates and teachers' perceptions to non-isolate ranges on standardized measurements.

Several points regarding the following investigation seem noteworthy, Social skill gains during treatment phases represent a conservative estimate of change since observation routinely occured the day after treatment. The isolate children initially displayed reticence to being in a group play situation, and required prompting to deliver reinforcement during the first four to five days of Intervention I. Independent delivery of reinforcement coincided with graphical increases in the target behavior during this phase.

Daily frequency data yielded valuable information about the topography of social responding in pre-schoolers. Vocal-verbal and motor-gestural play initiations were behaviors easily understood and emitted by the children. Conversely, neither isolates nor non-isolates displayed positive reinforcement skills such as praising or complimenting other children during daily sessions. Warren, Baer, and Rogers-Warren (1981) report a similar lack of praising skills in the pre-school population seemingly due to the indifference of the children to peer social praise. Negative behaviors appeared only sporadically, and did not increase during treatment despite previous findings of 
increased aggression during intervention (Kirby \& Toler, 1970). As previously noted (Conger \& Keane, 1981; Hops \& Greenwood, 1981), hovering was an unreliable measure of isolation since some isolates increased approaches to groups, while others displayed less movement between groups during treatment phases.

The use of SAMPLE measures provided a standardized assessment of isolation by which the practical significance of treatment gains could be addressed. At six month followup, isolates attained standardized interaction scores in the 50th percentile using four and five year old norms compared to their initial baseline levels in the 5 th percentile. Teachers' perceptions of change were congruent with daily skill increases for four of the five isolate children at three week follow-up. Although Subject 3 displayed the highest frequency of play initiations across phases, no change in social responding was perceived by the teacher at three week follow-up. This teacher's perception of the child as withdrawn did not correspond to the increase in frequency of interaction, nor did the child emit negative behaviors. It may be that the teacher was responding to other variables, e.g., that the child's family was experiencing marital difficulties at the time. Although SBR+ ratings at six month follow-up showed continued gains for all children, these findings should be 
viewed cautiously. New teachers and differing setting characteristics may have contributed to the higher interaction scores. However, this explanation receives little support from previous investigations. Past studies have typically found poor treatment maintenance (Conger \& Keane, 1981) and generalization to new settings (Michelson \& Wood, 1980).

Regarding the increased frequency of play initiations in the isolate peer modifiers, it should be noted that at no time during treatment did the isolates receive direct reinforcement for initiating play. Reinforcement was provided only for the correct identification of play initiations and subsequent reinforcement delivery to peers. The vicarious reinforcement model may partially explain these findings. While acting as peer modifier in treatment sessions, the isolates observed various play initiations and associated consequences. Vicarious reinforcement effects (Kazdin, 1979) were maximized by the conspicuousness of the reinforcers in that the isolates delivered praise and tokens to peers.

It has been suggested that vicarious reinforcement procedures be incorporated into treatments to fade individuals from direct to social reinforcement (Kazdin, 1979). Similarly, Combs and Slaby (1977) emphasize that behaviors shaped by adults will not be maintained in 
the natural setting if not enhanced by peer reinforcement. It seems likely that in the present study vicarious reinforcement in the form of anticipation of adult or peer reward accounted for the initial appearance of isolate play initiations during free play. However, given the subsequent maintenance and generalization of skills long after adult contingencies were terminated, isolates appeared to have learned behaviors which were spontaneously reinforced by peers in the natural setting. This maintenance of social behavior by peer reinforcement is the desired culmination of most social skills interventions, and circumvents the need for programmed generalization or weaning from adult reinforcement.

Most social skill treatments have demonstrated immediate increases in social responding using a variety of interventions. Long-term follow-up is frequently absent, and when included shows poor maintenance and generalization of skills over time (Conger \& Keane, 1981; Hops \& Greenwood, 1981). Unfortunately, comparisons of the magnitude or clinical significance of treatment effects in past studies are difficult to make because of the disparate dependent variables employed. For example, 0.Connor (1972) reported stable increases in social responding (e.g., reciprocal interactions) nine weeks after a modeling intervention, but included no comparisons 
to non-isolate baselines or sociometric status. Using a combined modeling and coaching strategy, Walker, Greenwood, Hops and Todd (1978) found direct contingencies increased specific types of play skills (e.g., initiations, positive responses, behaviors to maintain play), but at the expense of overall interaction levels, with no followup included. Strain, Shores, and Timm (1977) reported impressive increases in isolate vocal-verbal and motorgestural play initiations as a function of receiving confederate initiations, but no follow-up was obtained. Oden and Asher (1977) performed a one year follow-up on a coaching intervention and found sociometric and interactive gains maintained in the grammar school population, but no comparison was made to non-isolate groups.

Although the present findings may be generalizable only to similar pre-school populations, the intervention successfully increased isolate children's specific play initiations, overall interaction levels, and teachers' perceptions of withdrawal to non-isolate ranges. Maintenance and generalization of these gains at six month follow-up were most likely due to the vicarious and natural contingency effects previously detailed. The intervention included several components of previous modeling and contingency treatments, but did not require fading of adult reinforcement or programmed generalization 
to maintain learned behaviors. An additional advantage of acting as peer modifier was the placement of the isolate child in a competent reinforcing role, which precluded extensive training or regrouping of children in classrooms.

Future research using isolate children as peer modifiers should include diverse populations of withdrawn subjects and various social skills to assess the scope and generalizability of treatment effects. The use of sociometric measures may also be advantageous to determine whether changes in peer perceptions occur as a result of intervention. Finally, a dismantling strategy or comparison of modeling and direct reinforcement is needed to determine the relative contributions of these components. 
Figure Caption

Figure 1. Isolate vocal-verbal and motor-gestural play initiations across experimental phases.

Open circles represent vocal-verbal initiations.

Triangles represent motor-gestural initiations.

Missing data points are the result of student absences due to illness. 


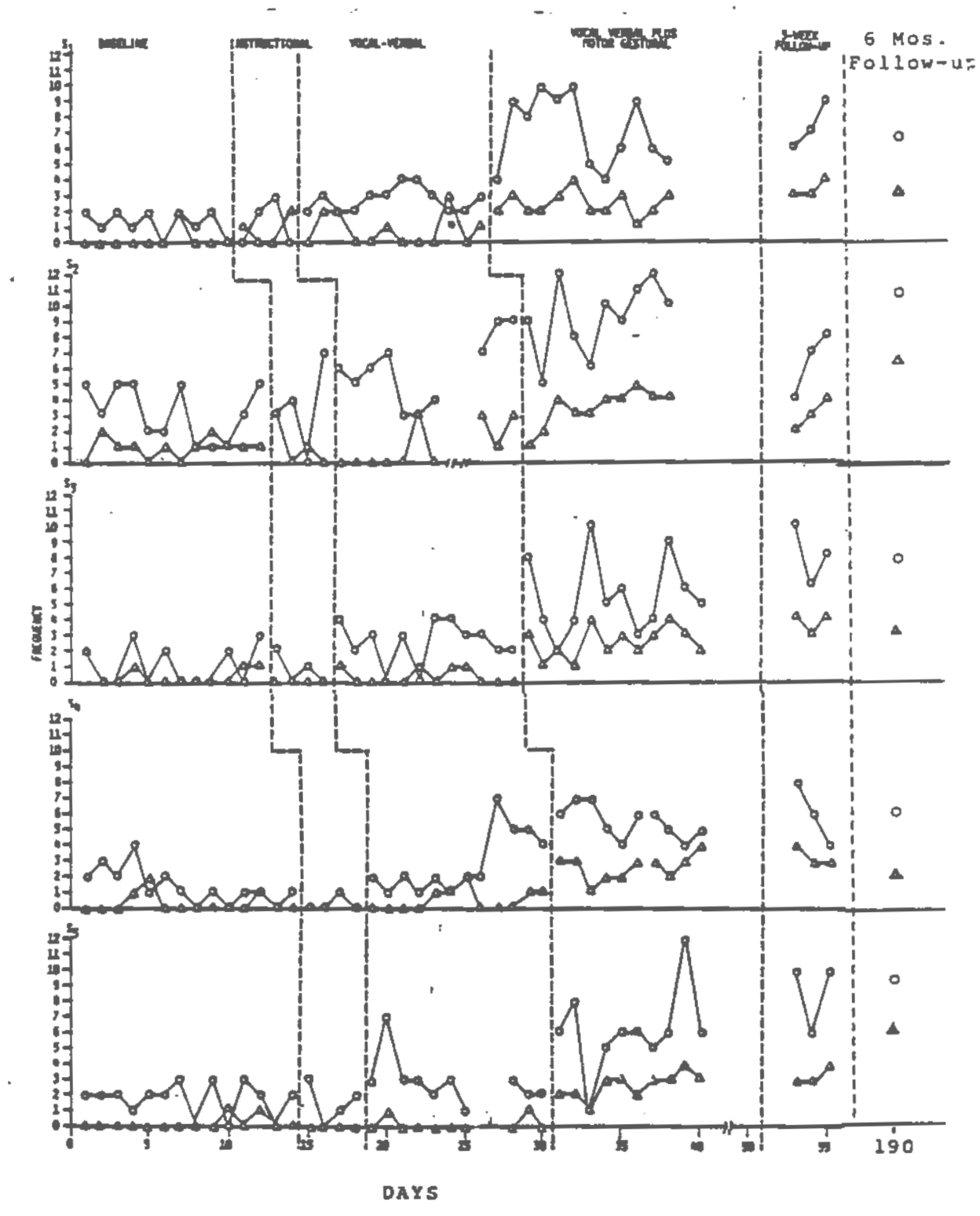


TABLE 1

Inter-rater Reliability Estimates Per Subject

Percent Agreement Occurence of Behavior

$\begin{array}{cccc}\text { Subject } & \overline{\mathrm{X}} & \text { Range } & \begin{array}{c}\text { Number of Observation } \\ \text { Days }\end{array} \\ & & & \\ 1 & .96 & .87-.99 & 13 \\ 2 & .89 & .85-.96 & 12 \\ 3 & .96 & .91-.98 & 14 \\ 4 & .92 & .88-.95 & 14 \\ 5 & .93 & .91-.97 & 13\end{array}$

Percent Agreement Non-occurence of Behavior

$\begin{array}{llll}1 & .96 & .95-.99 & 13 \\ 2 & .98 & .95-.99 & 12 \\ 3 & .96 & .91-.99 & 14 \\ 4 & .97 & .91-.98 & 14 \\ 5 & .97 & .93-.98 & 13\end{array}$


23.

THBLI 2

Isolate Means of Daily Frequency Measures Per Phase

VOCAL-VERERL PLAY INITIATIONS

\begin{tabular}{|c|c|c|c|c|c|c|c|c|c|c|}
\hline \multirow[t]{2}{*}{ Subject } & \multicolumn{2}{|c|}{ Baseline } & \multicolumn{2}{|c|}{ Intervention If } & \multicolumn{2}{|c|}{ Intervention II } & \multicolumn{2}{|c|}{3 Follow-up } & \multicolumn{2}{|c|}{$6 \mathrm{Mbs}$. Follon-up* } \\
\hline & $\bar{x}$ & 5 & $\bar{x}$ & 50 & $\overline{\mathrm{y}}$ & 50 & $\overline{\mathrm{x}}$ & SD & $x$ & SD \\
\hline 1 & 1.3 & 0.8 & 2.7 & 0.8 & $7.1^{\prime}$ & 2.2 & 7.3 & 1.5 & 6.0 & - \\
\hline 2 & 3.0 & 1.6 & 5.8 & 2.8 & 9.2 & 2.3 & 6.3 & 2.1 & 11.0 & - \\
\hline 3 & 1.0 & 1.2 & 2.5 & 1.3 & 5.5 & 2.4 & 8.0 & 2.0 & 8.0 & - \\
\hline 4 & 1.2 & 1.1 & 2.9 & 1.9 & 5.5 & 1.1 & 6.0 & 2.0 & 7.0 & - \\
\hline 5 & 1.7 & 1.1 & 3.0 & 2.5 & 6.1 & 2.7 & 8.6 & 2.3 & 10.0 & - \\
\hline \multicolumn{5}{|c|}{ "WIOR-GESTURAL PLAY INITIATIOUS } & & & & & & \\
\hline 1 & 0.2 & 0.6 & 0.7 & 0.2 & 2.4 & 0.8 & 3.3 & 0.6 & 3.0 & - \\
\hline 2 & 0.9 & 0.6 & 1.0 & 1.3 & 3.4 & 1.1 & 3.0 & 1.0 & 7.0 & - \\
\hline 3 & 0.3 & 0.6 & 0.3 & 0.5 & 2.5 & 1.0 & 3.6 & 0.6 & 3.0 & - \\
\hline 4 & 0.3 & 0.6 & 0.5 & 0.7 & 2.5 & 0.8 & 3.3 & 0.6 & 3.0 & $=$ \\
\hline 5 & 0.2 & 0.3 & 0.2 & 0.4 & 2.6 & 0.0 & 3.3 & 0.6 & 6.0 & - \\
\hline
\end{tabular}

¿Data comprised of single observation. 
TAELE 2, contd.

\section{POSITIVE REDTFORCFIPNT}

\begin{tabular}{|c|c|c|c|c|c|c|c|c|c|c|}
\hline subjects & Pac & ine & Inte & $\operatorname{inn} I$ & Inter & in If & 3. Theok & Follow & 6 Mos. & Follow-up* \\
\hline & & SD & $\bar{x}$ & $\$$ & $\overline{\mathrm{x}}$ & SD & $\overline{\mathrm{x}}$ & SD & $x$ & 50 \\
\hline 1 & 0.0 & 0.0 & 0.0 & 0.0 & 0.1 & 0.2 & 0.0 & 0.0 & 1.0 & - \\
\hline 2 & 0.2 & 0.5 & 0.3 & 0.6 & 0.1 & 0.3 & 0.0 & 0.0 & 0.0 & - \\
\hline 3 & 0.1 & 0.3 & 0.1 & 0.3 & 0.3 & 0.4 & 0.0 & 0.0 & 0.0 & - \\
\hline 4 & 0.7 & 0.2 & 0.0 & 0.0 & 0.2 & 0.4 & 0.0 & 0.0 & $\therefore 0.0$ & - \\
\hline 5 & 0.1 & 0.2 & 0,0 & 0.0 & 0.1 & 0.3 & 0.0 & 0.0 & 0.0 & - \\
\hline LDSTTVE & cars & & & & & & & & & \\
\hline 1 & 0.3 & 0.6 & 0.2 & 0.4 & 0.1 & 0.3 & 0.3 & 0.6 & 0.0 & - \\
\hline 2 & 0.1 & 0.3 & 0.0 & 0.0 & 0.3 & 0.6 & 0.0 & 0.0 & 0.0 & $=$ \\
\hline 3 & 0.1 & 0.3 & 0.0 & 0.0 & 0.1 & 0.3 & $n .0$ & 0.0 & 0.0 & - \\
\hline 4 & 1.3 & 0.9 & 0.2 & 0.4 & 0.4 & 0.7 & 1.0 & 1.0 & 0.0 & - \\
\hline 5 & 0.3 & 0.6 & 0.3 & 0.7 & 0.4 & 0.7 & 0.3 & 0.7 & 0.0 & - \\
\hline HOVERING & & & & & & & & & & \\
\hline 1 & 2.3 & 2.0 & 0.9 & 0.9 & 0.8 & 0.7 & 0.3 & 0.6 & 1.0 & - \\
\hline 2 & 1.8 & 1.5 & 1.3 & 1.4 & 0.5 & 0.7 & 0.0 & 0.0 & 0.0 & - \\
\hline 3 & 2.3 & 1.8 & 0.9 & 1.0 & 0.5 & 0.8 & 0.7 & 1.1 & 0.0 & - \\
\hline 4 & 1.4 & 1.6 & 0.7 & 0.9 & 1.0 & 0.9 & 0.3 & 0.6 & 1.0 & - \\
\hline 5 & 1.07 & 1.1 & 1.3 & 0.7 & 0.7 & 0.7 & 0.0 & 0.0 & 0.0 & - \\
\hline
\end{tabular}

- Data comprised of single observation. 
TABLE 3

Between Fhase Comparisons of Vocal-Verbal and Motor-

Gestural Behaviors Per Subject Using Time-Series Analysis

\section{VOCAL-VERBAL PLAY INITIATIONS}

Baseline/Intervention I

$\begin{array}{ccccccc}\text { Subject } & \begin{array}{c}\text { Dependency } \\ \text { (Phi) }\end{array} & \begin{array}{c}\text { Error } \\ \text { Variance }\end{array} & L^{1} & L^{2} & \text { t stat. df } \\ 1 & -0.04 & 0.62 & 1.3 & 1.5 & 4.46 * * & 20 \\ 2 & 0.48 & 3.13 & 3.5 & 2.4 & 1.93 & 20 \\ 3 & -0.26 & 1.64 & 1.0 & 1.5 & 3.63 * * & 22 \\ 4 & 0.50 & 1.86 & 1.4 & 1.4 & 1.53 & 24 \\ 5 & -0.26 & 1.57 & 1.7 & 1.3 & 3.08 * & 22\end{array}$

Baseline/Intervention II

$\begin{array}{rrrrrrr}1 & 0.20 & 3.13 & 1.3 & 5.6 & 6.18^{*} & 20 \\ 2 & 0.02 & 4.02 & 3.1 & 6.1 & 6.99^{*} & 20 \\ 3 & -0.08 & 3.74 & 1.0 & 4.5 & 6.10^{*} & 22 \\ 4 & 0.32 & 1.12 & 1.3 & 4.2 & 7.00^{*} & 22 \\ 5 & -0.18 & 3.60 & 1.7 & 4.4 & 6.49 * * & 22\end{array}$

MOTOR-GESTURAL PLAY INITIATIONS

Baseline/Intervention I

$\begin{array}{rrrrrrr}1 & -0.18 & 0.76 & 0.2 & 0.5 & 1.72 & 20 \\ 2 & -0.16 & 1.12 & 1.0 & 0.0 & 0.18 & 20 \\ 3 & 0.04 & 0.34 & 0.4 & 0.1 & 0.36 & 22 \\ 4 & 0.22 & 0.39 & 0.3 & 0.2 & 0.73 & 24 \\ 5 & -0.22 & 0.14 & 0.1 & 0.1 & 0.46 & 22\end{array}$

Baseline/Intervention II

$\begin{array}{rrrrrrr}1 & -0.12 & 0.61 & 0.2 & 2.2 & 7.93^{*} & 20 \\ 2 & 0.24 & 0.82 & 1.0 & 2.4 & 4.85^{*} & 20 \\ 3 & 0.10 & 0.74 & 0.4 & 2.1 & 5.35^{* *} & 22 \\ 4 & 0.18 & 0.50 & 0.3 & 2.4 & 6.88 * * & 22 \\ 5 & 0.18 & 0.35 & 0.1 & 2.5 & 8.38 * * & 22\end{array}$

$\mathrm{L}^{1}=$ Level

$I^{2}=$ Leve 1 Change 
Table 4

Isolate Scores on the SBRt

\begin{tabular}{cccc}
\hline Subject & Pre-treatment & \multicolumn{2}{c}{ Post-treatment } \\
& & Three weeks & Six months \\
\hline 1 & 3.2 & 3.7 & 3.1 \\
3 & 2.6 & 2.6 & $5.2^{\prime}$ \\
4 & 1.6 & 2.3 & $5.3^{\prime}$ \\
5 & 1.7 & $4.1^{\prime}$ & $4.0^{\prime}$ \\
& 1.5 & $4.5^{\prime}$ & $6.2^{\prime}$ \\
\hline
\end{tabular}

- Average range. 


\section{Table 5}

Isolate Scores on the soS

Pre-treatment

Post-treatment

Three weeks

Six months

Isolates

$\begin{array}{llrl}1 & .05 & 1.88 \cdots & 1.6 \cdots \\ 2 & .24 & .55 \% & 1.5 \% \\ 3 & .14 & .65 \% & 1.3 \cdots \\ 4 & .33 & 1.2 \% & 1.2 \cdots \\ 5 & .04 & 1.9 \cdots & 1.2 \%\end{array}$

- SAMPLE average range.

- SAMPLE above average range. 
Table 6

\author{
Repeated Measures ANOVA For Isolate \\ Group Means on SAMPLE Measures
}

SBR+ ANOVA Summary Table

\begin{tabular}{lcrl} 
Source & Sum of Sqs. & df & MS \\
Between & 1.5 & 4 & 0.4 \\
Within & 27.6 & 10 & 2.7 \\
Treatment & 17.5 & 2 & 8.7 \\
Residual & 10.1 & 8 & 1.2 \\
Total & 29.1 & 14 & 2.1 \\
$\mathrm{~F}_{\mathrm{T}}=0.6 \mathrm{n.s.}$ & $\mathrm{df}=(2.8)$ & & \\
\hline
\end{tabular}

SOS ANOVA Summary Table

$\begin{array}{lcrl}\text { Source } & \text { Sum } \text { of Sqs. } & \text { df } & \text { MS } \\ \text { Between } & 1.5 & 4 & 0.4 \\ \text { Within } & 7.9 & 10 & 0.8 \\ \text { Treatment } & 4.4 & 2 & 2.2 \\ \text { Residual } & 3.4 & 8 & 0.4 \\ \text { Total } & 6.3 & 14 & 0.5\end{array}$

$\underline{F}_{T}=5.5 \quad(p=.05), d f=(2,8)$ 


\section{REFERENCES}

Allen, K.E., Hart, B., Buell, J.S., Harris, F.R., \& Wolfe, M. M. Effects of social reinforcement on isolate behavior of a nursery school child. Child Development, $1964,35,511-518$.

Charlesworth, R. \& Hartup, w. W. Positive social reinforcement in the nursery school peer group. Child Development, $1967,38,993-1002$.

Cobb, J.A. The relationship of discrete classroom behaviors to fourth grade academic achievement. Journal of Educational Psychology, 1972, 63, 74-80.

Combs, M. \& Slaby, D. Social skills training in children. In A. Kazdin \& B. Lahey (Eds.), Advances in Clinical child psychology. New York: Plenum Press, 1977.

Conger, J.C. \& Keane, S.P. Social skills interventions in the treatment of isolate or withdrawn children. Psychological Bulletin, 1981, 90, (3), 478-495. Cooke, S.R., Cooke, T.P., Apolloni, T. Developing nonretarded toddlers as verbal models for retarded classmates. Child Study Journal, 1978, ㅁ, 1-8. Cowen, E.I., Pederson, A., Babijian, H., Izzo, L.A., \& Trost, M.A. Long-term follow-up of early detected vulnerable children. Journal of Consulting and Clinical Psychology, 1973, 41, 438-446. 
Glass, G.V., Wilson, V.I., \& Gottman, J.M. Design and analysis of time-series experiments. Boulder: Colorado Associated University Press, 1975. Greenwood, C.R., Todd, N.M. Walker, H.M., \& Hops, H. Social Assessment Manual for Preschool Level. Eugene: Center at Oregon for Research in the Behavioral Education of the Handicapped, 1978. Harrop, J.W. \& Vellicer, W.F. A comparison of three alternative approaches to time-series analysis.

Paper presented at the meeting of the Psychometric Society, Montreal, June, 1982. Hops, H., \& Greenwood, C.R. Social skills deficits.

In E.J. Mash \& I.G. Terdal (Eds.), Behavioral Assessment of Childhood Disorders. New York: Guilford Press, 1981.

Hyme I, S. \& Asher, S.R. Assessment and training of isolated children's social skills. Paper presented at the biennial meeting of the Society for Research in Child Development, New Orleans, March, 1982. Kazdin, A.E. Vicarious reinforcement and punishment in operant programs for children. Child Behavior Therapy, $1979,1,(1), 13-37$. Kirby, F.D. \& Toler, H.C. Modification of pre-school isolate behavior: A case study. Journal of Applied Behavior Analysis, $1970,3,309-314$. 
Lancioni, G.E. Normal children as tutors to teach social responses to withdrawn mentally retarded schoolmates: Training, maintenance, and generalization. Journal of Applied Behavior Analysis, 1982, 15, 17-40. Michelson, L. \& Wood, R. Behavioral assessment and training of children's social skills. Progress in Behavior Modification, $1980,2,242-287$.

O'Connor, R.D. Modification of social withdrawal through symbolic modeling. Journal of Applied Behavior Analysis, 1969, 2, 15-22.

O'Connor, R.D., The relative efficacy of modeling, shaping, and combined procedures. Journal of Abnormal Psychology, 1972, 79, 327-334.

Oden, S. \& Asher, S. Coaching children in skills for friendship making. Child Development, 1977, 48, 495-506.

Peck, C.A., Apolloni, T., Cooke, T.P., \& Raven S.A. Teaching retarded pre-schoolers to imitate the free play behavior of non-retarded classmates. Journal of Special Education, 1978, 12, 195-207. Phillips, E.L., Phillips, E.A., Wolf, M.M. \& Fixen, D.L. Achievement Place: Development of the elected manager system. Journal of Applied Behavior Analysis, $1973, \underline{6}, 541-562$.

Roff, M. Childhood social interactions and young adult bad conduct. Journal of Abnormal and Social 
Psychology, 1961, 63, 333-337.

Siegal, L.J. \& Steinman, W.M. The modification of a peer observer's classroom behavior as a function of his serving as a reinforcing agent. In E. Ramp \& G. Semb (Eds.), Behavior analysis and application. Englewood Cliffs: Prentice-Hall, Inc., 1975. Simonton, D.K. Cross-sectional time-series experiments: Some suggested statistical analysis. Psychological Bulletin, 197?, 84, 489-502.

Strain, P.S., \& Kerr, M.M. Modifying children's social withdrawal: Issues in assessment and clinical intervention. Progress in Behavior Modification, $1981, \underline{2}, 203-249$.

Strain, P.S., Kerr, M.M., \& Ragland, E.W. Effects of peer-mediated social initiations and prompting/ reinforcement procedures on the social behavior of autistic children. Journal of Autism and Developmental Disorders, 1979,2 , 41-54.

Strain, P.S., Shores, R.E., \& Kerr, M.M. An experimental analysis of the 'spillover effect' on the social interaction of behaviorally handicapped pre-school children. Journal of Applied Behavior Analysis, $1976,2,31-40$.

Strain, P.S., Shores, R.E. \& Timm, M.A. Effects of peer initiations on the social behavior of withdrawn 
pre-school children. Journal of Applied Behavior Analysis, 1974, ?, 583-590.

Strain, P.S. \& Timm, M.A. An experimental analysis of social interaction between a behaviorally disordered pre-school child and her peers. Journal of Applied Behavior Analysis, 1974, ?, 583-590.

Suratt, P.R., Ulrich, R.R., \& Hawkins, R.P. An elementary

student as a behavioral engineer. Journal of Applied Behavior Analysis, 1969, 2․ 85-93.

Ullmann, C.A. Teachers, peers, and tests as predictors of adjustment. Journal of Educational Psychology, 1957, 48, 257-287.

Walker, H.M., Greenwood, C.R., Hops, H., \& Todd, N.M. Differential effects of reinforcing topographical components of social interaction. Behavior Modification, 1979, 2, 291-321.

Warren, S.F., Baer, D.M., \& Rogers-Warren, A. Teaching children to praise: A problem in stimulus and response generalization. Child Behavior Therapy, 1979, 1, (2), 123-137.

Wiesen, A.E., Hartley, G., Richardson, C., \& Raske, A. The retarded child as a reinforcing agent. Journal of Experimental Psychology, 1967, 5, 109-113. 


\section{APPENDIX I}

\section{INFORMED CONSENT}

The purpose of this study is to explore ways in which children can increase in the amount of positive contact with their peers or classmates. Twelve children will participate in 30 minute play sessions, four times per week, over a 10 week period. During the first $15 \mathrm{mins}$. of the play session the children will be observed while they play freely. During the second $15 \mathrm{mins}$. of the play session, your child may play one of two roles. He/she may either receive training from the investigator in how to show other children that he/she likes or approves of what they are doing or may receive praise and reinforcement for good or friendly social behaviors.

The results of this study will be used to develop new ways to teach children social skills and to have better relationships with friends. This study is being completed in partial fulfillment of Master's degree requirements under the direct supervision of Drs. Allan Berman and Mark Rapport and the research results may be published. Your child's name will not be used in any reports of the data. Your child's right to confidentiality will be respected at all times.

Voluntary cooperation and participation may be withdrawn at any time by the child or the parent. Parents may meet at any time with the experimentor to discuss concerns related to their child's participation in the study. This project was developed and is affiliated with the University of Rhode Island Department of Psychology, and any related questions or concerns should be addressed to the investigators.

No detrimental effects are foreseen to the children. The possible benefits to the children include increases in their positive social and play behaviors, and a more rewarding play environment. 
40.

A. I have explained the above description to (Name of Parent/Legal Guardian and believe that he/she understands the above information.

Investigator Signature Date

B. I understand the information above relating to the participation of my child (student's name), and I hereby consent to his/her participation in the project.

Signature of Parent/Legal Guardian Date 


\title{
INFORMED CONSENT-COVER LETTER
}

\author{
* Please address any questions to: \\ Diane Marques 438-9500 ext. 83
}

February 2, 1982

Mark D. Rapport, Ph.D. 792-2193

\section{Dear Parents,}

I am a third year doctoral candidate in clinical psychology at the University of Rhode Island. Currently I am working at Weeting Street School, and finishing up my Master's degree requirements.

Your child's nursery school has consented to allow me to run some play groups in the school which are designed to teach children how to be good playmates, how to make friends, and how to cooperate in a group. The groups will run for about a half hour per day over a ten week period, and will be conducted during the children's regular play periods. The benefits to all children involved would be increased recognition of good behavior, and positive reinforcement for social and play skills.

Right now I am asking your permission for Dr. Mark Rapport and myself to observe your child in his/her daily routine for about one hour over the week of Feb. 8-15. We will simply be recording the frequency of some kinds of social behaviors your child engages in. Your child's right to confidentiality will be respected at all times. If we are interested in your child's participating in these play groups you will be contacted by the investigators. Enclosed is a more extensive description and consent form for participation in the play groups. This study has been approved by U.R.I.'s research review board which protects the rights of subjects.

In closing, I would again like to ask your permission for us to observe your child at school. We will be contacting you again if we would like your child to participate in the play groups. Thank you for your attention to this matter.

Sincerely yours,

Diane Marques 
Yes, the investigators may observe my child for purposes of inclusion in the play groups.

No, the investigators may not observe my child for purposes of inclusion in the play groups. 


\section{APPENDIX II}

DAILY RECORD SHEET

sctont

OASPTVE
$\operatorname{InC/PN} / \mathrm{Ym}$

$D A^{*}:$ :I $T_{-}$! TI
PLAY AROIT

TIT:

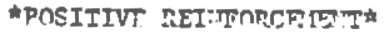

1. Ver! al exrression of lilee

2. Pralse for cargets $(\nabla / v ;: q / \sigma)$.

3. Talbe for non-target behaviors

\#VTrAL / VRT:TAL

4. Initlations/1nvitations to nlav.

5. Attembts to share nlavthlng.s.

f. Bupgestions to structure plav.
*tTTOR_GTCTTRAL

7. rodily folns groun.

G. Prrsically leads neer

Into pla"

r. Gestures which stat alay.

\#TCAITUE, FEIAVIOR*

1C. Verbal Insults, screaming,etc.

11. Pegative gestures

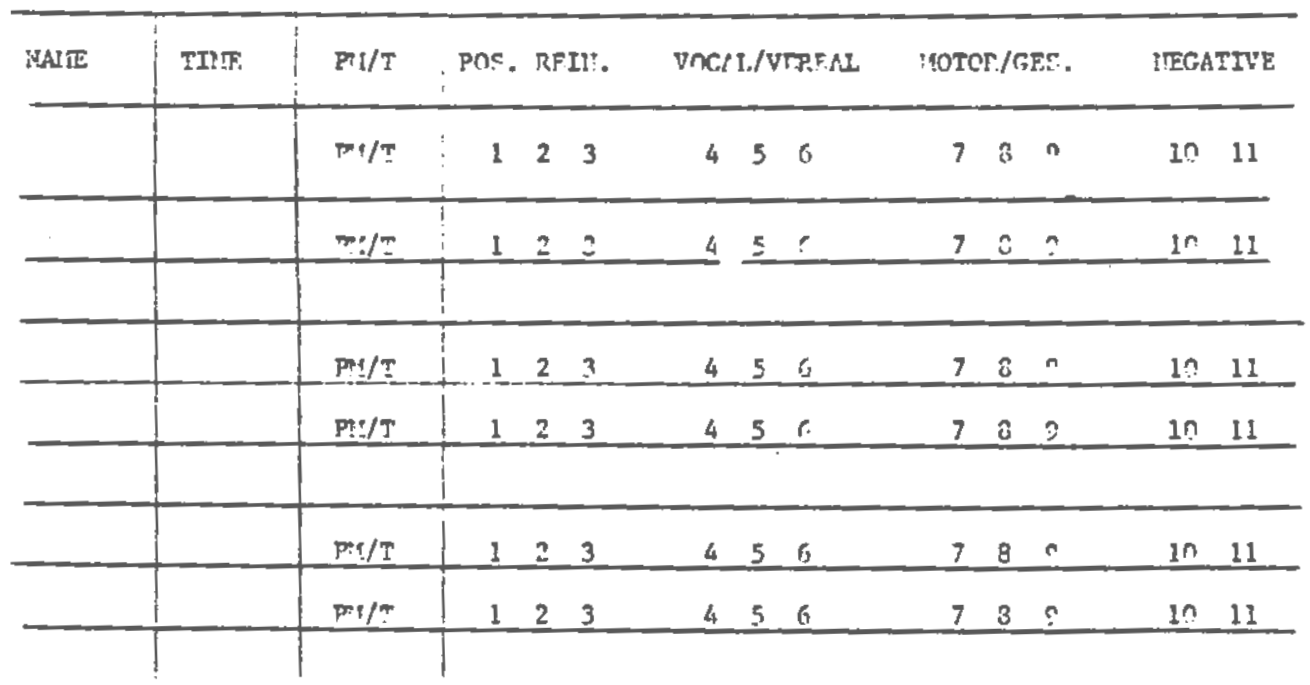

$(8+5 \times 14)$ 


\section{APPENDIX III}

Summary of Non-isolate Data

Non-isolate children benefited from the present treatment by gaining positive reinforcement for two classes of play initiations. Although these skills were present in the children's behavioral repertoires prior to treatment, play initiations did increase, as did interaction levels. The following data were collected to ensure that non-isolates in addition to isolates benefited from contingencies, and for anecdotal comparison purposes to isolates. 


\section{APPENDIX IIIa.}

\section{Inter-Rater Reliability Estimates \\ Per Subject for Non-isolates}

Percent Agreement Occurence of Behavior

Subject $\overline{\mathrm{X}}$ Range Number of Observations
6
$.95 \quad .91-.97$
$.93 \quad .85-.95$
8
.95
$.91-.96$
9
.88
$.84-.94$
10
.92
$.92-.93$

Percent Agreement Non-Occurence of Behavior

$\begin{array}{rlll}6 & .96 & .95-.96 & 3 \\ 7 & .96 & .88-.99 & 3 \\ 8 & .98 & .97-.99 & 3 \\ 9 & .96 & .95-.96 & 3 \\ 10 & .97 & .94-.99 & 3\end{array}$


46.

APPENDIX IIIb.

Non-isolate Means of Daily Frequency

Measures Per Phase

VOCAL-VERBAL PLAY INITIATIONS

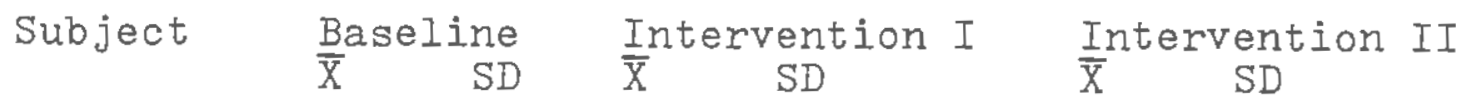

$\begin{array}{ccccccc}6 & 3.3 & .81 & 7.0 & 1.7 & 8.0 & 3.0 \\ 7 & 1.6 & .81 & 6.6 & 1.9 & 6.6 & 1.2 \\ 8 & 2.6 & 1.6 & 6.6 & 1.9 & 8.3 & 1.1 \\ 9 * & 3.3 & .81 & 6.3 & 1.7 & - & - \\ 10 & 2.3 & .75 & 9.6 & 4.0 & 6.6 & 4.7\end{array}$

MOTOR-GESTURAL PLAY INITIATIONS

$\begin{array}{ccccccc}6 & 1.0 & 1.0 & 1.0 & 1.7 & 5.0 & 2.0 \\ 7 & 0.0 & 0.0 & 0.0 & 0.0 & 3.6 & 1.0 \\ 8 & 0.0 & 0.0 & 0.3 & .58 & 2.3 & .75 \\ 9 * & 0.0 & 0.0 & 0.6 & .67 & - & - \\ 10 & 0.6 & 1.1 & 0.6 & .58 & 5.0 & 1.0\end{array}$

POSITIVE REINFORCEMENT

$\begin{array}{ccccccc}6 & 0.0 & 0.0 & 0.3 & .58 & 0.0 & 0.0 \\ 7 & 0.3 & .58 & 0.0 & 0.0 & 0.0 & 0.0 \\ 8 & 0.0 & 0.0 & 0.3 & .58 & 0.0 & 0.0 \\ 9 * & 0.0 & 0.0 & 0.0 & 0.0 & - & - \\ 10 & 0.0 & 0.0 & 0.0 & 0.0 & 0.0 & 0.0\end{array}$

NEGATIVE BEHAVIORS

$\begin{array}{ccccccc}6 & 0.0 & 0.0 & 0.0 & 0.0 & 0.0 & 0.0 \\ 7 & 0.3 & .58 & 1.0 & 1.7 & 0.0 & 0.0 \\ 8 & 0.6 & 1.1 & 1.0 & 0.0 & 0.6 & 1.1 \\ 9 * & 0.0 & 0.0 & 1.0 & 0.0 & - & - \\ 10 & 0.0 & 0.0 & 0.0 & 0.0 & 0.0 & 0.0\end{array}$

HOVERING

$\begin{array}{ccccccc}6 & 1.3 & 1.2 & 0.3 & .58 & 0.3 & .58 \\ 7 & 0.3 & .58 & 0.3 & 1.7 & 1.0 & 0.0 \\ 8 & 0.3 & .58 & 0.0 & 0.0 & 0.0 & 0.0 \\ 9 * & 3.0 & 1.0 & 2.3 & .75 & - & - \\ 10 & 0.6 & 1.1 & 1.0 & 1.0 & 1.3 & 1.2\end{array}$

*Missing data points due to illness. 


\section{APPENDIX IIIC.}

\section{Non-Isolates Scores on the SOS}

Subject

6
7
8
9
10
Pre-Treatment

$.76^{\circ}$

$.85^{\prime}$

$1.1 \%$

$1.2 \times$

$1.2^{\prime \prime}$
Post-treatment

$$
\begin{aligned}
& 1.2 . ' \\
& 1.1 \% \\
& 1.8 \% \\
& 1.2 \% \\
& 2.1 \%
\end{aligned}
$$

- Average Range

-Above Average Range 